\title{
Dimensions of Environmental Engineering
}

\author{
Birgitta Dresp-Langley*
}

Department of Mechanical and Civil Engineering, LMGC, UMR 5508 CNRS, Montpellier, France

\begin{abstract}
The impact of human activity on the biosphere has produced a global society context in which scarcity of natural resources and risks to ecological health such as air pollution and water contamination call for new solutions that help sustain the development of human society and all life on earth. This review article begins by recalling the historical and philosophical context from which contemporary environmental engineering has arisen as a science and domain of technological development. Examples that deal with some of the core issues and challenges currently faced by the field, such as problems of scale and complexity, are then discussed. It is emphasized that the sustainability of the built environment depends on innovative architecture and building designs for optimal use and recycling of resources. To evaluate problems related to global climate change, storms, floods, earthquakes, landslides and other environmental risks, the behaviour of the natural environment needs to be taken into account. Understanding the complex interactions between the built environment and the natural environment is essential in promoting the economic use of energy and waste reduction. Finally, the key role of environmental engineering within models of sustainable economic development is brought forward.
\end{abstract}

\section{INTRODUCTION}

Global society and the dominance of the human species over the biosphere have provoked a situation where ecological and environmental engineering are the inevitable professional response to the most pressing problems of humankind. The goal of both theoretical and practical environmental engineering is to help society function. Combining theory, research, practice, and education defines the basis for exchange of knowledge relative to engineering solutions that are socio-economically justifiable, responsible, and consistent with a sustainable development of communities, populations, and nations. Such solutions aim at planning, designing, and improving structures, facilities, and infrastructures for a responsible, economic, and efficient use of energy resources. For the protection of the health of man and the environment, environmental engineering involves identifying and preventing contaminant behaviours in man-made and natural systems, and, above all, to minimize the negative impact, or ecological footprint, of humankind on all systems and cycles upon which life depends. This article proposes a brief review of the historic background facts, philosophical considerations, theoretical concepts, and pragmatic issues from which contemporary environmental engineering has arisen, as both a scientific discipline and a domain of applied research and development.

\section{HISTORICAL AND PHILOSOPHICAL BACK- GROUND}

The Industrial Revolution marked a turning point in the history of humankind. Towards the end of the 1700s, manual labour-based economy was progressively replaced by industry and the manufacture of machinery. Large scale production of chemicals significantly contributed to the economic

*Address correspondence to this author at the Department of Mechanical and Civil Engineering, LMGC, UMR 5508 CNRS, Montpellier, France; Tel: +33 (0)4 671446 81; Fax: +33 (0)4 671439 23;

E-mail: dresp@lmgc.univ-montp2.fr development and concomitant pollution of the natural environment brought about by the Industrial Revolution, with the production of sulphuric acid, hydrochloric acid, and alkalis. Trade expansion was facilitated by the introduction of railway systems. Steam powered machinery engendered dramatic increases in production capacity and the technological developments and engineering breakthroughs of the Industrial Revolution promoted urbanisation. The rapid growth in urban populations increased the demands for produce from outside the cities, and the ecological footprint of whole countries soon reached beyond their borders, leading the way towards modern global economy [1]. Some philosophers reacted to the Industrial Revolution through writings that reintroduced and emphasized the profound relationship between man and nature. Ralph Waldo Emerson's book Nature is one such example [2]. The book is, in fact, a compelling essay in which Emerson defines nature as an all-encompassing entity which is inherently known to us rather than being merely a component of the outside world. Emerson's philosophy established, especially in the US, a way of looking at man and his natural environment which placed nature at the centre of humanity. Others, such as Henry David Thoreau were influenced by Emerson's writings. Emerson took a philosophical standpoint which marked a significant point in the history of science and, in particular, of the biological and contemporary neurosciences by advocating the idea that the natural world and the mental world, or workings of the human brain, are bound to have common biological origins. Both Emerson's and Thoreau's writings contributed significantly to environmentalism as a philosophy and a political and social movement concerned with the conservation and improvement of the natural environment, both for its own sake and in regard to its importance to civilization and life in general. Later, Aldo Leopold's book A Sand County Almanac [3] became a key reference which reinforced the ethical standpoint of environmentalist philosophy, arguing that it is unethical to harm the natural environment, and that humankind has a moral duty to respect and protect it. The ethical 
standpoint has significantly influenced the science of modern environmental engineering and economics $[4,5,6]$. While the engineering community showed little interest in environmental issues for a long time after the Industrial Revolution, this situation changed with Richard Buckminster Fuller, a pioneering scholar and engineer who was one of the first of his kind to promote environmental issues as a core topic of both fundamental and applied science. His ideas and writings have contributed substantially to the development of the theory and practice of contemporary environmental engineering.

\section{ENGINEERING FOR 'LIVINGRY': RICHARD BUCKMINSTER FULLER'S PIONEERING VISION}

Richard Buckminster Fuller was born in 1895 in Massachusetts and, expelled from Harvard University as a student, subsequently became a prominent early environmental activist and scholar, initiating and collaborating in innovative design projects with professionals, artists, and scientists worldwide. An engineer, architect, designer, developer, scientist and scholar, he registered a large number of US Patents for his innovations. Buckminster Fuller lectured at leading Universities all over the world and devoted his professional practice and teachings to applying engineering and the principles of science to solve problems of society, aware that humankind would soon have to rely on renewable sources of energy. His anticipatory vision of a planet running dry of natural resources was confirmed by the Millennium Ecosystems Assessment (MEA) no later than two decades after his death in 1983, with the conclusion that human activity has over the last few decades altered ecosystems more rapidly and extensively and accelerated global climate change more noticeably than in any comparable time span in the history of man. Way ahead of his time, Richard Buckminster Fuller promoted a systemic approach to environmental issues. His work explored solutions for energy and material-efficient engineering and design such as

- foldable emergency shelters

- lightweight building structures

- renewable resources and recycling

- aerodynamic vehicles

- wind energy solutions for large buildings and individual households

- tap and shower systems that help reduce water consumption

Fuller's prototype of a curve-shaped, energy-efficient, low-cost, modular and transportable living structure designed in the 1940s, the 'Dymaxion House' (see Fig. 1 below), was equipped with innovative technology exploiting natural winds for cooling and ventilation and featuring individual taps and showers with economic spray systems to help reduce water consumption.

In his book Critical Path [7], Buckminster Fuller resolutely and passionately advocates the idea of doing more with less. He argues for an efficient and economic use of natural resources, and promotes the search for solutions that sustain the development of all forms of life on Earth. He can be regarded as the father of engineering for sustainability, and his philosophy was definitely a forerunner of the modern

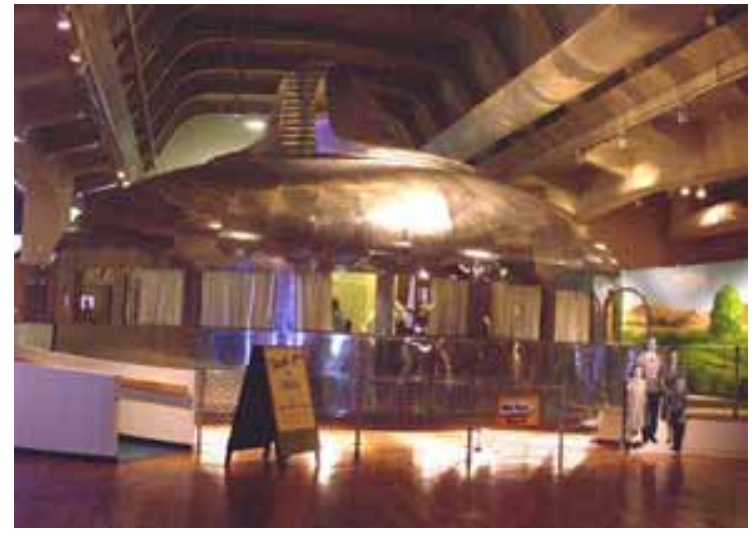

Fig (1). Richard Buckminster Fuller's prototype of energy efficient individual housing, the Dymaxion House, is displayed at the Henry Ford Museum in Dearborn, Michigan, US.

anthropocentric approach [8] to the environmental sciences. His teachings and whole conception of education were focussed on fostering the development of life-long skills covering a broad range of knowledge and competence to achieve what he called an "omni-successful education"; his view of science was in essence an inter-disciplinary one. The concept of 'livingry', which Fuller invented as opposed to 'weaponry', laid the theoretical foundations on which the modern concept of sustainable development is grounded. His integrative view of engineering science can be summarized by the schematic model shown in Fig. 2 below.

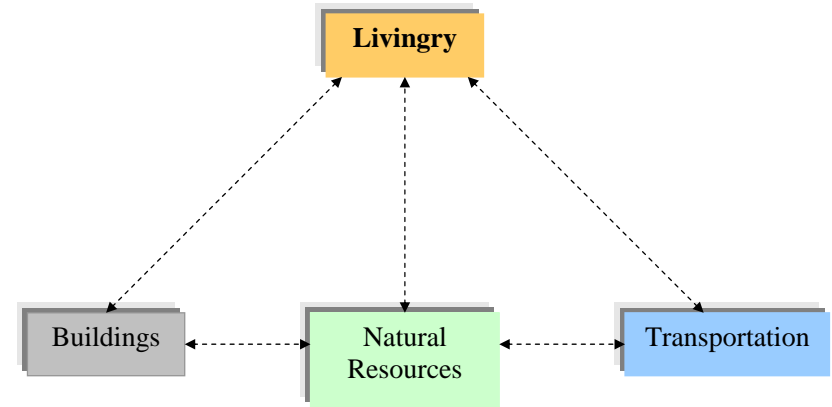

Fig (2). Fuller's world-view can be regarded as the first anthropocentric vision of the natural and built environment, where manmade facilities and transport exploit and exhaust raw materials and natural energy resources such as air and water, which are essential per se (red arrow) for sustaining human and other life on Earth ("livingry"). Fuller predicted that natural resources would soon be jeopardized by over-exploitation and pollution. He is considered to be one of the first engineering scientists to have consistently and actively promoted renewable energy solutions and waste recycling.

The impact of human engineered systems on the natural environment has become a global issue of the highest importance since Fuller's death in 1983. The grander goals of modern engineering have since been concerned with the remediation and prevention of environmental pollution and the exhaustion of raw materials and other natural resources.

\section{FROM ECOSYSTEM STUDIES TO ENVIRON- MENTAL ENGINEERING}

From the 1960s systems ecology blossomed as a discipline within the biological sciences. Ecosystem approaches contributed to increase knowledge on how the atmosphere 
responds to the combined effects of global metabolism and geochemical recycling, and how these biogeochemical processes are in turn influenced by changes in the atmosphere. The seminal books by Eugene Odum and Howard Odum [9, 10] provide a complete review of the history and fundamentals of systems ecology. Systemic approaches in ecology draw from a wide range of scientific disciplines including geology, biochemistry, conservation biology and evolutionary ecology. Some authors [11] have attempted to subdivide the field of ecology into approaches concerned with biodiversity and the conservation of ecological entities ("compositionalism") on the one hand, and more systemic approaches aiming at understanding processes of ecosystem functioning ("functionalism") on the other. The reality of current research in the field, however, shows that integrative forms of ecological research are emerging, blurring the lines between specialized domains within and beyond ecology. Theoretical models tend towards increasingly global biosphere approaches, aiming at an understanding of the Earth as a whole. In the model of a balanced global biosphere, photosynthesis fixes carbon dioxide and regenerates oxygen while humans, animals, plants and microbes draft from the atmosphere by using oxygen and by generating carbon dioxide at an equivalent rate. In the real world, such balanced behaviour no longer exists. The major challenge for ecology now is to gain an understanding of large-scale effects causing imbalanced behaviour in the global biosphere, and to further our knowledge about underlying biogeochemical processes and how they interact. Engineering science has acquired a critically important role within this endeavour. Solutions to the most pressing problems of an imbalanced Earth are expected to result from adequate engineering development and technology, based on the interpretation of research models and observational data. Theoreticians have previously insisted on differences between ecological engineering and environmental engineering [12], the former being seen as essentially concerned with constraints on ecosystems and living organisms, while the latter would mainly address constraints on non-living environments and would therefore be more closely identified with "conventional" engineering $[12,13]$. Such views fly in the face of the fact that engineering has evolved dramatically over recent years towards increasingly global and integrative approaches to society problems, in parallel with major advances in the fields of the fundamental life sciences, computer sciences, and design technologies. The idea of a theoretical separation between issues and topics of ecological engineering on the one hand and environmental engineering on the other is now difficult to reconcile with contemporary engineering, both in terms of research and practice. The necessity of replacing the entire domain of science within a context of urgency has produced a situation where "conventional engineering" is a thing of the past. With the introduction of the concept of sustainability in terms of a global challenge [14] hitting almost any field of modern science and technology and therefore reaching well beyond classic ecology, a significant shift in thinking has occurred. Global anthropocentric theories have begun to tighten existing links between scientific domains. These include links between mathematics, computer modelling, and economics [15], and links between the humanities and the social sciences to the benefit of environmental science [16].

\section{SUSTAINABILITY: FROM LOCAL COMMUNITY TO GLOBAL SOCIETY}

While the practice of environmental engineering has evolved considerably during the past two decades, its underlying contract with society has always been the same. Environmental engineering is about providing quality of life for all, with the protection, nurture and renewal of a fragile environment in mind. Environmental scientists predict that local communities and individual houses will generally become smaller, and will be based on principles of ecological design $[17,18]$, where the restoration of natural environments within urban landscapes is to play an important role. The ecological approach to the built environment involves a holistic design approach where energy use and resource depletion is reduced, and external and internal pollution causing potential damage to users and the environment is minimized. An example of such design at the level of individual housing is the Hockerton project, which was completed in Great Britain in 1996 and listed in the catalogue of "best practice" examples by the European Green Building Forum in 2001 [19]. In this project, rainwater from the roofs is filtered and collected as drinking water. Since plastic is likely to give off toxics, copper gutters are used. In order to save energy, water is heated with a pump. Water falling elsewhere on the estate is pumped to a reservoir large enough to hold several months' supply for washing laundry and growing crops. The reservoir's capacity is $150 \mathrm{~m}^{3}$, and the water runs trough a natural filter system. All sewage treatment systems are biological and rely entirely on natural organisms [18]. A mechanical aeration system recycles air and preserves heat within the building. Heating costs are minimized. Figure 3 shows how the houses in the Hockerton project were covered with earth to trap heat. Sustainable building design is the thoughtful integration of ecologically aware architecture and electrical, mechanical, and structural engineering. In addition to concerns for aesthetics, proportion, scale, texture and light, ecological long term costs are taken into account. Connecting building design with nature brings new forms of life to urban dwellings, and reminds us of our place within nature. Sustainable building design is to take into consideration a wide range of cultures, races, religions and habits to meet the needs of individuals and communities, at local and global scales.

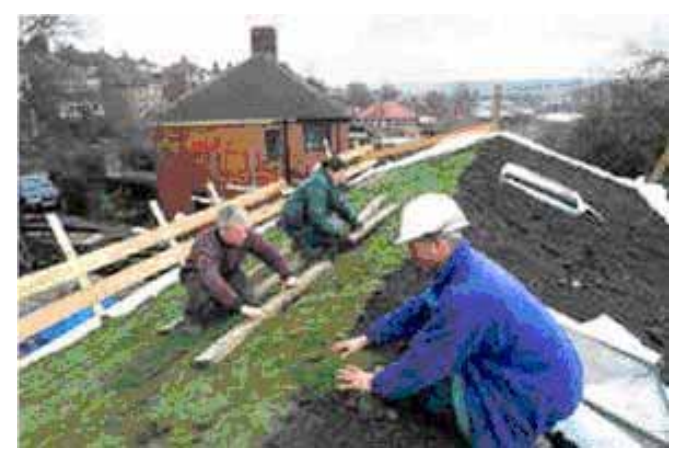

Fig (3). In the Hockerton Project (UK, 1996) roofs were covered with soil rather than tiles to increase energy efficiency by trapping heat. The soil acts as a giant radiator.

The field of environmental engineering is to face the challenge of an unprecedented global urbanization and in- 
dustrialization in developing countries such as Africa, which seek to increase their wealth and living standards. Engineers nowadays have to be able to adapt their vision and respond to the needs of societies at a much larger and more complex scale, where cooperation with and within other cultures is required. Among the most urgent demands currently put to the profession, we may list the following:

- educate the public to increase awareness of environmental issues

- mitigate the threats of global climate change

- provide adequate supplies of fresh water

- deal with the pressures of increasing population

- anticipate energy shortages, searching for renewable energy sources

- develop tools to assess the performance and sustainability of existing structures

- design ecologically friendly transportation systems

- estimate impacts and anticipate risks (earthquakes, floods, storms, contamination)

- restore and reclaim mined and disturbed landscapes

- develop and strengthen links with other fields of science such as mechanics, biochemical engineering, the geological, biological, computer, social and management sciences

These complex issues cut across all the engineering domains and require a scientific analysis at different levels of scale and complexity. Management training and expertise to put new solutions into practice is an essential aspect of modern environmental engineering. (Fig. 4) proposes a schematic view of problems to be addressed, at small and large scales.

\section{ADAPTIVE PROJECT MANAGEMENT TO COPE WITH PROBLEMS OF SCALE AND COMPLEXITY}

A factor which is often difficult to assess in the search for sustainable solutions is that of the scale and complexity of a given problem. Engineers may be perfectly capable of working out a basic physical design or the hydro-geomorphology for what may seem an appropriate solution to a problem of the environment, but may ultimately not provide a successful solution because the scale or complexity of the problem was not adequately predicted and analyzed. The complexity and scale of biological systems [20] make it difficult, sometimes impossible, to understand how these systems behave at different levels of organization from elemental cycles to community metabolisms, and how these levels interact. Moreover, biological systems and components [21] take different and variable times to respond to engineering solutions or to changes in general. The timescale of their responses may exceed that of reasonable monitoring expectations and may render reliable predictions impossible. This timescale problem can be illustrated by the example of damaged coastal reefs, where times for a full functional restoration at a site may be estimated in terms of centuries. Also, biological systems respond to changes as they develop, and this natural adaptation may make it difficult or impossible to work out ready regulatory recipes. A different but related problem of scale in environmental engineering is that related to the

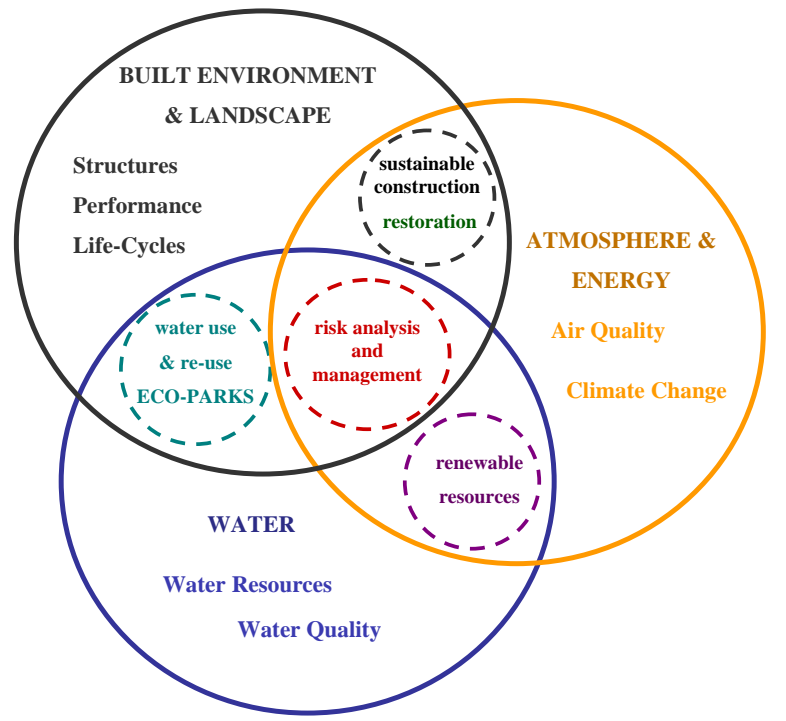

Fig (4). The built environment reflects the material wealth of cities and nations. Its sustainability largely depends on the care and rigor with which resource use and re-use, emissions, structural resistance to earthquake threats, land-fill volumes and other environmental factors are taken into account, from the planning, design, construction and anticipated life cycles to the demolition and re-use of buildings. Understanding interactions between the built environment and its natural context is essential for promoting an economic use of resources. Finding sustainable solutions involves research for renewable resources and the analysis and management of risks such as global climate change, earthquakes, floods or storms. The availability and consumption of energy influences both the nature and extent of pollution and the extent to which polluted atmosphere or polluted sites can be regenerated or restored (intersection between orange and grey circles). Countries with poorly developed infrastructures in which energy supply is scarce will have to cope with environmental problems at a different scale compared with countries which have highly developed infrastructures and extensive energy production and consumption.

number of people concerned or affected by a project. Adaptive project management was proposed as an approach that helps cope with problems of scale [22, 23]. Adaptive management allows for changing goals as an engineering project evolves with time. Intelligent monitoring combined with general project goals allow realistic re-evaluations of what can be accomplished. Adaptive management works best with a conceptual model that leads to clearly defined, explicit general goals [23]. The success criteria in adaptive project management vary from case to case, and the more success criteria depend on process and function per se, the more it is likely that general goals will be reached. For processes that are well understood, a list of detailed success criteria can be established from the outset. Most importantly, adaptive management permits the learning process inherent to modern engineering research and practice to be progressively integrated into a given project. As far as planning is concerned, any well-developed project plan should include a flow chart with branches at points in the process where uncertainty exists, and where deviation from an expected outcome pathway leads to an anticipated alternative endpoint. Well-designed engineering projects incorporate uncertainty into the process, and at the outset inform the public or responsible party of potential problems, alternative solutions, and their cost. 
These are represented by alternative pathways and endpoints in the project flow chart. Adaptive management allows all parties involved to consider a variety of potential endproducts and determine if they are acceptable. Marcus [24] discussed the example of a project for tidal marsh restoration in San Francisco Bay, which affected a large number of user groups in the area and required continual reworking of the engineering plans to satisfy the political and economic concerns expressed by these groups and the general public. Evaluating the impact of man-made damage or natural disasters on the environment and public concerned is another important, scale-dependent issue within the science and practice of environmental engineering.

\section{IMPACT STUDIES: ASSESSING DAMAGE AND LOSS OF RESOURCES}

Landscape planning and policy making are affected by the impact of both man-made and naturally caused damage to the environment. As an example, we may consider the case of earthquakes, such as that which occurred in September 1999 in Central Taiwan, inducing several large-scale landslides and causing environmental and resource problems which required a functional analytical ecosystem approach to the problem beyond the standard technological solutions. The impact study by Lin, Lin, \& Chou [25] gives an example of a long-term investigation into the consequences of earthquakes on the environment. In this study, changes of the post-quake landslides, vegetation recovery conditions, and soil loss were assessed using imaging technology such as multi-temporal SPOT satellite images, and analytical image transformation. Mathematical models for vegetation recovery analysis based on calculations of normalized difference vegetation index (NDVI) and Universal Soil Loss Equations [26] guided the research and evaluation. Landslides were identified on the basis of pre- and post-quake air images using image differencing algorithms and change detection thresholds. Vegetation recovery rates (VRR) were computed to quantify successive conditions of vegetation recovery at landslides. To estimate the environmental impact of the denudation sites, soil loss before and after the earthquake was calculated on the basis of geomorphology analysis. The research revealed large-scale impacts of the earthquake and the concomitant landslides, and enabled further decision making policies and planning in the affected areas. After six years of monitoring, vegetation recovery was found to have reached $89.69 \%$, which gives an overall assessment of nature's ability to regenerate vegetation after large-scale landslides. However, other risk factors such as typhoons could abolish such renewal in a short time. To mitigate such risks, engineering solutions for geo-morphologically unstable sites need to be developed. Other medium and large-scale risks that challenge the expertise of researchers and practitioners in the field of environmental engineering are those represented by the contamination of water supplies through toxic trace elements.

\section{RISK EVALUATION AT MULTIPLE LEVELS OF ORGANIZATION}

Inadequate water supply and related health hazards are a daily problem faced by millions of people worldwide. The management of the water environment for sustainable human benefit requires environmental policies that promote eco- logical health, meaning both ecosystem health and human safety. The concerns of environmental engineers for water supplies, the mitigation of contamination, and the promotion of ecological health nowadays extend beyond the performance and safety of individual components. Entire water supply systems and their interactions with other systems are taken into account, which involves evaluating the risks and analyzing the consequences of water contamination by pathogens or toxic trace elements. These may originate from various sources. Metal traces in soils, for example, were found to cause potentially contaminant effects at all levels of biological organization, from cellular to ecosystem levels, even in sites where the corresponding surface water met water quality criteria [27]. The presence of COPECs, or contaminants of potential environmental concern [28] in soil and water represents an ecological risk at the ecosystem, community, population, individual, cellular, and molecular levels. While the detection and identification of COPECs as such is, in principle, not difficult, the current problem with toxicity risk evaluation is that the specificity of contaminant effects, and the insight gained into the mechanisms of toxicity as such, is lesser the higher the level of organization [29]. Indicators of toxicity such as morphological changes at the tissue level, ultra-structural changes at the cellular level revealed through electron microscopy, and biochemical changes at the molecular level permit establishing and to quantifying cause-effect relationships. Evaluation of contamination risks at the level of ecologically relevant processes is far more difficult and susceptible to biases due to the lack of individual data on exposure, outcomes, or confounding variables that may contribute to a measured effect [30]. At lower levels of organization, critical changes occur more rapidly and may provide early warnings of toxicological effects on populations $[29,30]$. However, despite the greater mechanistic understanding and specificity of effects at lower levels of organization, the insight provided may be limited because the significance of these effects at the ecological level or the amplitude of their bio-magnification is unknown. The usefulness of indicators thus depends on the cross examination of multiple levels of organization. Effects of traceelements on plant communities, for example, may be relevant because the production of plant matter is a primary source of organic carbon for aquatic ecosystems. A possible food-chain transfer from contaminated soils should also be considered. Changes at the ecosystem level may be inferred when contaminants exceed benchmark levels that are toxic to soil bacteria, suggesting that their functional properties related to nutrient cycling and energy flow have been affected [27]. The pathways for the migration of contaminants away from a given source may involve transport in surface water and shallow groundwater. Although dissolved metal trace elements in water may seem harmless with respect to toxicity, this does not alleviate concerns over oral uptake of trace elements through contaminated food. It is generally believed that the uptake of adsorbed trace elements is significantly less dangerous than the absorption of dissolved forms [31]. However, the relative importance of the different routes of exposure remains unclear and at high concentrations the bioavailability of even a small fraction of adsorbed trace elements from diet could be important, which would support the hypothesis that diet is a significant route of exposure [32, 33]. At the level of human populations, the risk of mortality 
from cancer is estimated to be increased in people exposed to certain trace elements through diet, even at seemingly low concentrations [34]. Eco-toxicology has, for the last 30 years, been concerned with studying the effects of contaminants on the biological integrity and ecological health of communities and ecosystems. Newman and Unger [35] give a complete and comprehensive overview, from the general principles of eco-toxicology to examples of scientific indepth studies. Some of these are concerned with the effects of environmental pollutants at different levels of biological organization, from the molecule to the biosphere as a whole. How biotic integrity can be assessed at different levels, and used as a monitoring tool to guide further investigation, is discussed. To restore the ecological health of water, soils, and sediments, ecological and environmental engineering design solutions are applied to an increasingly diverse range of innovative projects for the effective management of natural resources. Adequate technologies have been created and are currently used within the fields of environmental protection and restoration, the food sector, industrial waste and sewage treatment, and architecture and landscape design. These technological solutions are the core of turn-key strategies aimed at reducing the negative impact of humankind on natural resources.

\section{TURN-KEY STRATEGIES TO RESTORE ECOLOGI- CAL HEALTH}

Environmental engineering practice is all about what Aronson et al [8] called "the search for effective turnkey strategies to mitigate or overturn the negative environmental effects of the $20^{\text {th }}$ century's growth path". A turnkey strategy, in business language, is a strategy or solution where the provider or designer (research and development) undertakes the entire responsibility from design to completion and commissioning. The client (society) only has to turn the proverbial key to make the solution function as it should. Several concrete examples of environmental turn-key solutions at the medium scale are given in the case examples presented by Todd, Brown, \& Wells [18]. Their applied functionalist approach shows how engineered ecosystem designs and concepts can be readily applied to solve concrete environmental problems such as

- sewage treatment through biologically diverse, vascular and woody plants, which are particularly suitable for waste treatment

- restoration of contaminated water by floating devices using wind and solar energy

- $\quad$ organic industrial waste treatment

- ecologically designed systems for air purification, humidity control, water re-use, waste treatment and food production within architectural structures

- the integration of industrial and agricultural activity sectors in urban design and landscape planning through the creation of eco-parks

The economic viability of integrative ecosystems and environmental engineering design within urban settings is a topic that concerns both the general public [36] and local authorities involved in planning and decision making. Urban environments provide the basis for most of the world's eco- nomic activities, including tourism and the leisure industry. Urban planning and development has a major impact on the economic performance of companies, corporations and nations, affecting human activities at all levels. Demographic estimates of a large number of additional inhabitants of the planet for the next decade require planning and development of basic housing and infrastructures, which is to incur a gigantic cost to support the predicted population growth. At the same time, infrastructures are rapidly decaying in many countries and are urgently in need of repair and maintenance, which represents projects associated with another enormous outlay. The increasing trans-national embedding of global sustainability issues will lead to private-public partnerships and projects that will be delicate to manage, especially in developing countries that do not have a tradition of private ownership and public infrastructure. Thus, both scientists and professionals in the field of environmental engineering will be confronted with unprecedented social and economical challenges.

\section{ENVIRONMENTAL ENGINEERING AND SUSTAIN- ABLE ECONOMIC DEVELOPMENT}

Whether an innovative design solution that benefits the environment and the people who live in it will ultimately meet success depends on economical and social factors. Questions of cost-effectiveness or whether people are likely to accept and live with a solution proposed to them need to be addressed. Idealistic visions have to lead to realistic outcomes and ethical concerns are to be taken into account in the light of economical and political pressure. This involves cost-benefit analyses, feasibility studies and awareness of the political climate and decision making context as potential limiting factors to a project. The emerging discipline of ecological economics addresses such complex problems at the interface of the economic system and the global ecosystem that sustains and contains it. Like environmental engineering, ecological economics espouses a systems approach that aims to offer solutions to the problems of society in the 21 st century. Economics is generally defined as the science of allocation of scarce resources among alternative desirable ends. This implies a specific sequence of steps in economic analysis and, finally, the economist must decide what ends are to be pursued. Many argue that decisions on ends should be left to democratic processes, suggesting that an essential precursor to economic analysis is the democratic process that successfully articulates the desired goals. Once these latter have been identified, the economist can analyze what resources are necessary to achieve them, and which of these resources are the scarcest. The final step is allocation, via whatever institution or mechanism is most appropriate for the resources and ends considered [17]. In classical economics, there is no absolute resource scarcity. As a resource becomes scarce, its price increases, which provides market incentives to develop substitutes. The problem with such reasoning is that the human and all other species rely for their survival and welfare on hitherto non-marketed ecosystem services such as climate, air, water, and a clean atmosphere. Though increasingly scarce, most of these services have no price and therefore do not generate any feedback from markets to indicate their scarcity. Theoretical economics concentrates on growth and on markets, but markets fail to efficiently allocate most natural resources [37], possibly 
with the exception of water, given that there is now water pricing in many areas, at least for urban and industrial use. The critical problem is that, as an economy grows, it does not expand into a void, but into a finite sustaining and containing biosphere. Throughout the process of economic growth, society exhausts natural capital, and thereby its vital support functions. The potential irreversibility of this process has sometimes been discussed on the example of energy consumption and the second law of thermodynamics [38]. This universal law of increasing entropy or increasing unavailability of energy in a physical system predicts that in any isolated system entropy increases. Applied to the economic process, as discussed by Georgescu-Roegen [38], the second law of thermodynamics leads to predict that, ultimately, the scarcest energy resource will be low-entropy matter-energy. The ability of societies to rely on such energy would thus, ultimately, be limited. On the other hand, there is an anticipated abundance of a variety of renewable, nonpolluting forms of energy [17], and the development of innovative engineering solutions that are radically different from current designs will play an important role in environmental engineering as the $21^{\text {st }}$ century progresses. The search for society forms capable of allocating resources in a sustainable and effective way has become a topic of major concern world-wide. Economists [15, 39, 40] now question the classic economic growth models, which postulate a quantitative increase in the rate at which an economy transforms natural resources into economic output and waste. New theories of economic development, which incorporate concepts of a development ethic [6] and "dematerialization", have been proposed, such as Robert Ayres' theory [40], which insists on the difference between "more" and "better", and which challenges the classic growth paradigm by pointing out that the relevant measure of economic output is not the quantity of goods produced, but the quality and the, not necessarily material, value of final services provided to the consumer. Such worldviews tend to separate the economic process from energy and material issues, and place priorities on increasing the quality of human life and well-being while limiting resource use and waste production. The reinvestment of capital produced by global economy into environmental engineering research and the development of innovative technology and solutions will become an important strategy to such an end. Figure 5 here below illustrates these implications.

\section{CONCLUSIONS}

Contemporary environmental engineering is about developing systems, structures, methods, tools and infrastructures that help protect human health and the environment, including sustainable transportation and energy systems, and solutions for safe and adequate water supply worldwide. Problems have to be analyzed on a large scale, taking into account the growing trans-national embedding of environmental research and technology. The examples discussed here illustrate how the theory, research and practice of environmental engineering, in contact with other disciplines such as ecology, geology, biology and economics, address the most urgent problems currently faced by global society. Understanding complex systems requires more than one model, and there is a growing agreement on the need for exchange across the natural, engineering and social sciences to address

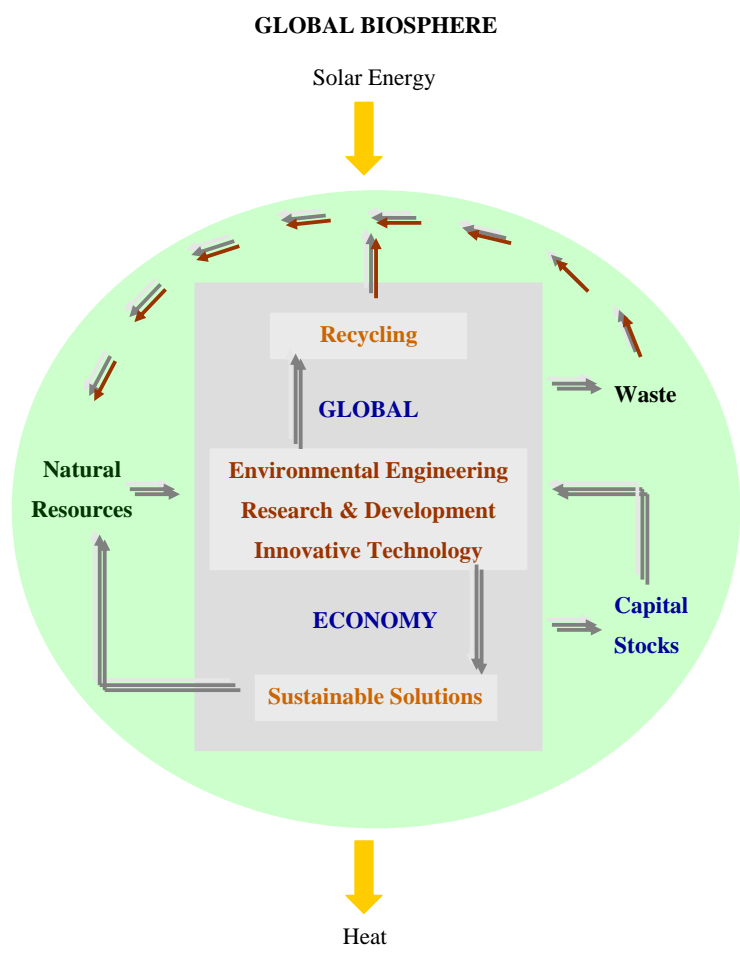

Fig (5). Growing economy does not expand into a void, but into a finite sustaining and containing biosphere. Through the process of economic growth, society exhausts natural capital and thereby its vital support functions. Modern economic science searches for models of economic development capable of allocating resources in a sustainable and effective way, where human welfare is sustained, natural resources are protected and restored, and waste production is reduced. This must involve the sound but eager re-investment of capital stocks produced through economic development into research and innovative technology promoting new, sustainable solutions.

questions of sustainability and economic development, the increasing scarcity of natural resources, and the future of the biosphere as a whole. The need for new engineering solutions is urgent, the stakes are high. By taking into account the social and psychological implications of these priorities, and by promoting exchanges between scientists across disciplines in close contact with the public, we may hope to be able to rise to the challenge.

\section{REFERENCES}

[1] D. S. Landes, The Unbound Prometheus: Technical and Industrial Development in Western Europe from 1750 to the Present. New York: Cambridge University Press, 2003.

[2] R. W. Emerson, Nature. James Munroe \& Co: Boston, 1836.

[3] A. Leopold, A Sand County Almanac. Oxford: Oxford University Press, 1949.

[4] H. E. Daly, and J. Cobb, For the common good: redirecting the economy towards community, the environment, and a sustainable future. Boston: Beacon Press, 1989.

[5] P. Dasgupta, Human well being and the natural environment. Oxford: Oxford University Press, 2002.

[6] J. N. Blignaut, "Towards an economic development ethic", in Sustainable options, J. N. Blignaut, M. P. de Wit, (Ed). Capetown: UCT Press, 2004, pp. 515-522.

[7] B. Fuller, Critical Path. New York: St. Martin's Press, 1981.

[8] J. Aronson, J. N. Blignaut, S. J. Milton, and A. F. "Clewell, Natural capital: The limiting factor". Ecol. Eng., vol. 28, pp. 1-5, 2006. 
[9] E. P. Odum, Fundamentals of Ecology. Philadelphia: Saunders, 1959.

[10] H. T. Odum, Environment, Power and Society. New York: Wiley, 1971.

[11] J. B. Callicott, L. B. Crowder, and K. Mumford, "Current normative concepts in conservation”, Conserv. Biol., vol.13, pp. 22-35, 1999.

[12] T. F. H Allen, M. Giampietro, and A. M. Little, "Distinguishing ecological from environmental engineering", Ecol. Eng., vol. 20, pp. 68-81, 2003.

[13] D. K. Gatti, M. C. Smith, E. W. Tollner, and S. C. Mc Cutcheon, "The emergence of ecological engineering as a discipline", Ecol. Eng., vol. 20, pp. 83-94, 2003.

[14] D. J. Painter, "Forty-nine shades of green: ecology and sustainability in the academic formation of engineers", Ecol. Eng., vol. 20, pp. 267-273, 2003.

[15] H. E. Daly, and J. Farley, Ecological economics - principles and applications. Washington: Island Press, 2004.

[16] A. Bandura, "Social cognitive theory: an agentic perspective", Ann. Rev. Psychol., vol. 52, pp. 1-26, 2001.

[17] J. Farley, and R. Costanza, "Envisioning shared goals for humanity: a detailed vision of a sustainable and desirable USA in 2100", Ecol. Econ., vol. 43, pp. 245-259, 2002.

[18] J. Todd, E. J. G. Brown, and E. Wells, Ecological design applied, Ecol. Eng., vol. 20, pp. 421-440, 2003.

[19] European Green Building Forum catalogue of best practice examples, The Hockerton Housing Project, Southwell, UK. The Netherlands: W/E Consultants Sustainable Building, 2001.

[20] V. C. Engel, and H. T. Odum, "Simulation of community metabolism and atmospheric carbon dioxide and oxygen concentrations in Biosphere 2", Ecol. Eng., vol. 13, pp. 107-134, 1999.

[21] K. Jax, "Ecological units: definitions and application", Quart. Rev. Biol., vol. 81, pp. 237-258, 2006.

[22] C. T. Hackney, Restoration of coastal habitats: expectation and reality. Ecol Eng., vol. 15, pp. 165-170, 2000.

[23] R. M. Thom, "Adaptive management of coastal ecosystem restoration projects", Ecol. Eng., vol. 15, pp. 365-372, 2000.

[24] L. Marcus, "Restoring tidal wetlands at Sonoma Bay-lands San Francisco Bay, California”, Ecol. Eng., vol. 15, pp. 373-383, 2000.

[25] W. Lin, C. Lin, and W. Chou, "Assessment of vegetation recovery and soil erosion at landslides caused by a catastrophic earthquake: A case study in Central Taiwan”, Ecol. Eng., vol. 28, pp. 79-89, 2006.
[26] J. P. Wilson, "Soil erosion from agricultural land in the Lake Simcoe Couchiching Basin -1800-1991", Can. J. Soil Sci., vol. 69, pp. 206-222, 1989

[27] D. Peplow, and R. Edmonds, "The effects of mine waste contamination at multiple levels of biological organization", Ecol. Eng., vol. 24, pp. 101-119, 2005.

[28] P. Calow P, Handbook of Environmental Risk Assessment and Management. Oxford: Blackwell Science, 1998.

[29] P. V. Hodson, "Indicators of ecosystem health at the species level and the example of selenium effects on fish", Environ. Monit. Assess., vol. 15, pp. 241-254, 1990.

[30] W. H. "Clements, Integrating effects of contaminants across levels of biological organization: an overview". J. Aquatic Ecosystems Stress Recovery, vol. 7, pp. 113-116, 2000.

[31] S. Tamaki, W.T. Frankenberger, "Environmental bio-chemistry of arsenic", Rev. Environ. Contam. Toxicol., vol. 124, pp. 79-109, 1992.

[32] R. Dallinger, and H. Krautzky, "The importance of contaminated food for the uptake of heavy metals by rainbow trout: a field study", Oecologia, vol. 67, pp. 82-89, 1985.

[33] L. Hare, "Aquatic insects and trace metals: bioavailability, bioaccumulation, and toxicity", Crit. Rev. Toxicol., vol. 22, pp. 327-369, 1992.

[34] Arsenic in Drinking Water 2001 Update. NAS-NRC Subcommittee on Toxicology, Board of Environmental Studies and Toxicology, Earth and Life Sciences Division. Washington: National Academy Press, 2001.

[35] M. C. Newman, and M. A. Unger, Fundamentals of Ecotoxicology, Second Edition. Chelsea: Lewis Publishers, 2002.

[36] J. Aronson, S. J. Milton, J. N. Blignaut, and A. F. Clewell, "Nature conservation as if people mattered", J. Nat. Cons., vol. 14, pp. 260263, 2006.

[37] G. Heal, Nature and the marketplace. Washington: Island Press, 2000.

[38] N. Georgescu-Roegen, The entropy law and the economic process. Cambridge: Har. University Press, 1971.

[39] J. Farley, and H. E. Daly, "Natural capital: the limiting factor-A reply to Aronson, Blignaut, Milton \& Clewell", Ecol. Eng., vol. 28 , pp. 1-5, 2006.

[40] R. Ayres, Turning point: the end of the growth paradigm. London: Earthscan, 1998 